their vision was the same whether they smoked the cannabis or took the extract.

I subsequently arranged a meeting with an ophthalmologist colleague, Dr Albert Lockhart, to discuss the possibility of there being a scientific basis to the claimed improvement to night vision. We were able to show that the effect must be due to some component of the cannabis and not the rum. After some years of work, which except in its later stages was carried out with only very limited personal funds and the University of the West Indies laboratory facilities, we prepared a nonpsychoactive substance from cannabis, which showed a marked ocular hypotensive effect. This preparation, Canasol, is now used to treat glaucoma, and many patients have reported significant improvement in night vision after taking it.

Lockhart had observed that the incidence of glaucoma seemed to be lower among the rastafarians in Jamaica. The members of this religious group use cannabis in many forms as part of their rituals, and it is known that lowering of intra-ocular pressure is related to cannabis use.

We turned our attention to the possible site and mechanism of this effect. There is an abundance of literature on the pharmacology of $C$. sativa. From our findings, some of which are unpublished, it would seem that adrenoreceptors are involved and that they may be located in the ciliary epithelium. The ocular responses can be antogonized by alpha-adrenoreceptor blocking agents, ligation of the ascending cervical (sympathetic) nerve, and retrobulbar anaesthesia. To date the mechanism of the improved night vision has not been elucidated. Although lack of money has prevented us from collaborating with ophthalmologists and pharmacologists outside Jamaica, our research continues.

M. E. WEST

Department of Pharmacology,

Faculty of Medical Sciences,

University of the West Indies,

Mona Campus,

Kingston 7 ,

Jamaica

\section{Too much Hg}

SIR - Basu et al. ${ }^{1}$, in discussing mercury released from crematoria, add 201,780 g plus $120,990 \mathrm{~g}$ plus $872,570 \mathrm{~g}$ to make 482 $\mathrm{kg}$. But these numbers actually add up to $1195.34 \mathrm{~kg}$. This means that all their following calculations are out by a factor of 2.48 .

So, for the crematorium studied by Mills ${ }^{2}$, the mass of mercury released should be $2.199 \times 2.48=5.453 \mathrm{~kg}$ per year. This is half-way to the $11 \mathrm{~kg}$ he estimated.

\section{St Christopher's Road, \\ Wildmill, \\ Bridgend, \\ Mid-Glamorgan CF31 1RV, UK \\ 1. Basu, M. K., Wilson, H. J. \& Krishnan, G. Nature 349, 109 (1991). \\ 2. Mills, A. Nature 346, 615(1990)}

\section{Gulf oil spill and the monsoon}

SIR - Attention throughout the world has been focused on one of the biggest environmental disasters caused by the large oil slick and the smoke from the burning of 600 oil wells as a result of the recent Gulf crisis.

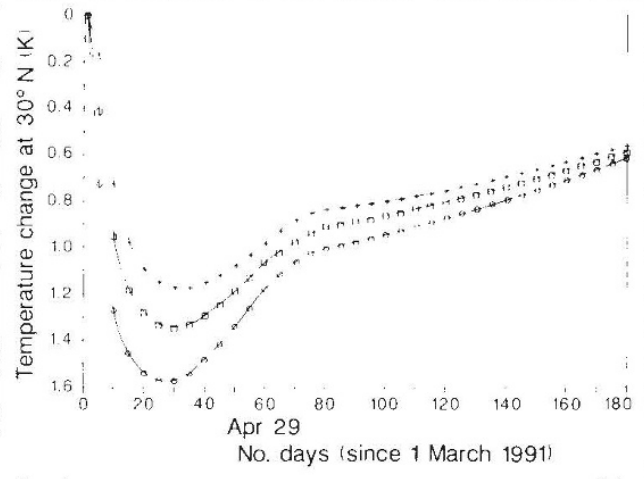

Surface cooling over the Indian subcontinent at $30^{\circ}$ $\mathrm{N}$ during spring and summer 1981 . Crosses, Tibet $\left(90^{\circ} \mathrm{E}\right)$; squares, India $\left(80^{\circ} \mathrm{E}\right)$; circles, Pakistan $\left(70^{\circ} \mathrm{E}\right)$.

From a detailed analysis of satellite imageries from INSAT-1B, NOAA-11 and IRS-1A, we conclude that the prolonged smoke from the burning oil wells will have a weakening effect on the Indian monsoon.

Satellite observations (including radiance measurements) show that the deliberate spillage of about 10 million barrels of oil, which started around 24 January, rapidly expanded during the initial 10-day period due to spreading, ocean dynamics and evaporation, to cover an area of more than $6,000 \mathrm{~km}^{2}$ from Mina Saud to Abu Ali along the Saudi coast. It stopped expanding further because by then the oil layer had sufficiently thinned to make surface-tension effects dominant ${ }^{1}$.

We have estimated the long-term effect of the continuous injection of more than 20,000 tons of smoke from the burning of more than 2.5 million barrels of oil each day on the surface temperature over the Indian subcontinent, assuming a continuous injection rate into the upper troposphere of 3 per cent. The absorption of solar radiation by smoke and its effect on temperature have been estimated for different models of oilwell capping, using the 'nuclear winter' model and taking into account the reduced injection of smoke into the troposphere with them due to the saturation effect.

Calculations for all realistic predictions indicate that the large-scale smoke injection will produce a surface cooling of about $8 \mathrm{~K}$ locally, a figure consistent with the observations. More important from the point of view of the Indian monsoon is the resulting long-

1. Hoult, D. P. A. Rev. Fluid Mech.4, 341-368 (1972).

2. Handler, P. J. geophys. Res. 91, 14475-14490 (1986).

3. Jones, P. D., Wigley, T. M. L. \& Kelly, P. M. Mon. Weath. Rev. $110,59-69(1982)$

4. Das, P. K. The Monsoons (National Book Trust, New Delbi 1968).

5. Hamilton M. G. Proc Int. Conf. Scient. Resuits Monex 6-21 (1981). term cooling of about $1.0-1.5 \mathrm{~K}$ over the Indian subcontinent, particularly over Pakis$\tan$, the Tibetan plateau and Delhi, the first two being critical synoptic thermal systems for driving the monsoon (see figure).

Any reduction in the overall solar radiation reaching the Earth will reduce the land-sea heating contrast. Observations of low-latitude volcanic explosions ${ }^{2}$ and analysis of 100 years of surface temperature data $^{3}$ show that reduction of temperatures by $0.5 \mathrm{~K}$ or more over the 'Pakistan heat low' and the 'Tibetan high' regions has a significant impact on the Indian monsoon. The former will weaken one of the two driving terms for the Somali jet, which brings moisture to India through evaporation over both the Indian ocean and the Arabian sea, resulting in the overall weakening of the monsoon ${ }^{4}$. Similarly, the cooling of about $1 \mathrm{~K}$ or more over the Tibetan high and the presence of soot, as confirmed by Monex results ${ }^{5}$, will cause a delay in the onset of the monsoon.

Although the monsoon is governed by several global factors, some of which may compensate for the adverse effects of oil smoke, continuous injection of smoke itself will result in regional cooling which will adversely perturb the onset and performance of the southwest monsoon in 1991 and, possibly, in 1992, unless compensated by other factors.

U. R. RAO

Indian Space Research Organisation, New Bel Road,

Bangalore 560094 ,

India

\section{Boring sperm}

SIR - By using the title "Sperm whale", Daedalus' research team emphasizes that it thinks only of aggression as a factor in sperm competition ${ }^{1}$. But the race is not to the swift. Having reached the neighbourhood of an ovum, sperm must bore through a mass of cumulus cells. When one gets into the ovum, entry of others is impeded; thus boring efficiency may be more important than swimming speed or aggression.

Cumulus is held together by hyaluronic acid; sperm carry hyaluronidase. Working on the assumption that this is not an accident and that boring is helped by hyaluronidase, we tested ${ }^{2}$ hyaluronidase inhibitors such as partly nitrated hyaluronic acid ${ }^{3}$ and found that they inhibit fertilization in rabbits. Daedalus' team would be well-advised to try hyaluronidase inhibitors as contraceptives, and hyaluronidase activators in the more aggressive aspects of its work.

\section{Leyton Road,}

N. W. PIRIE

1. Jones, D. Nature 351, 276 (1991).

2. Pincus, G. Pirie, N. W. \& Chang, M. C. Archs Biochem. 19 388.396 (1948).

Hadidian, Z. \& Pirie, N. W. Biochem. J. 42, 260-265 266-274 (1948) 